EUROPEAN CENTRAL BANK

WORKING PAPER SERIES

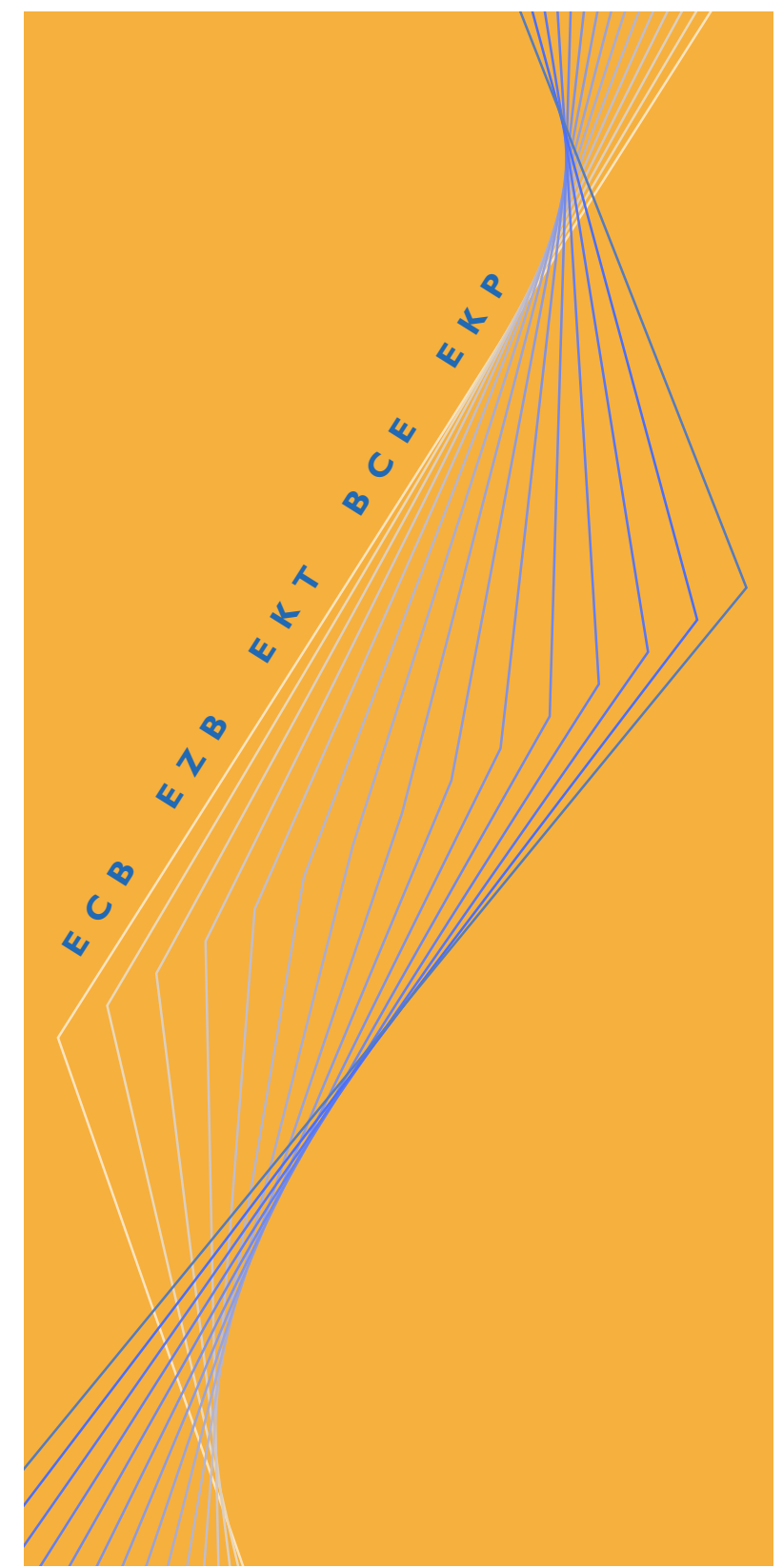

WORKING PAPER NO. 7 I

ASSET MARKET LINKAGES

IN CRISIS PERIODS

BY P. HARTMANN,

S. STRAETMANS AND

C.G. DE VRIES

July 200 I 


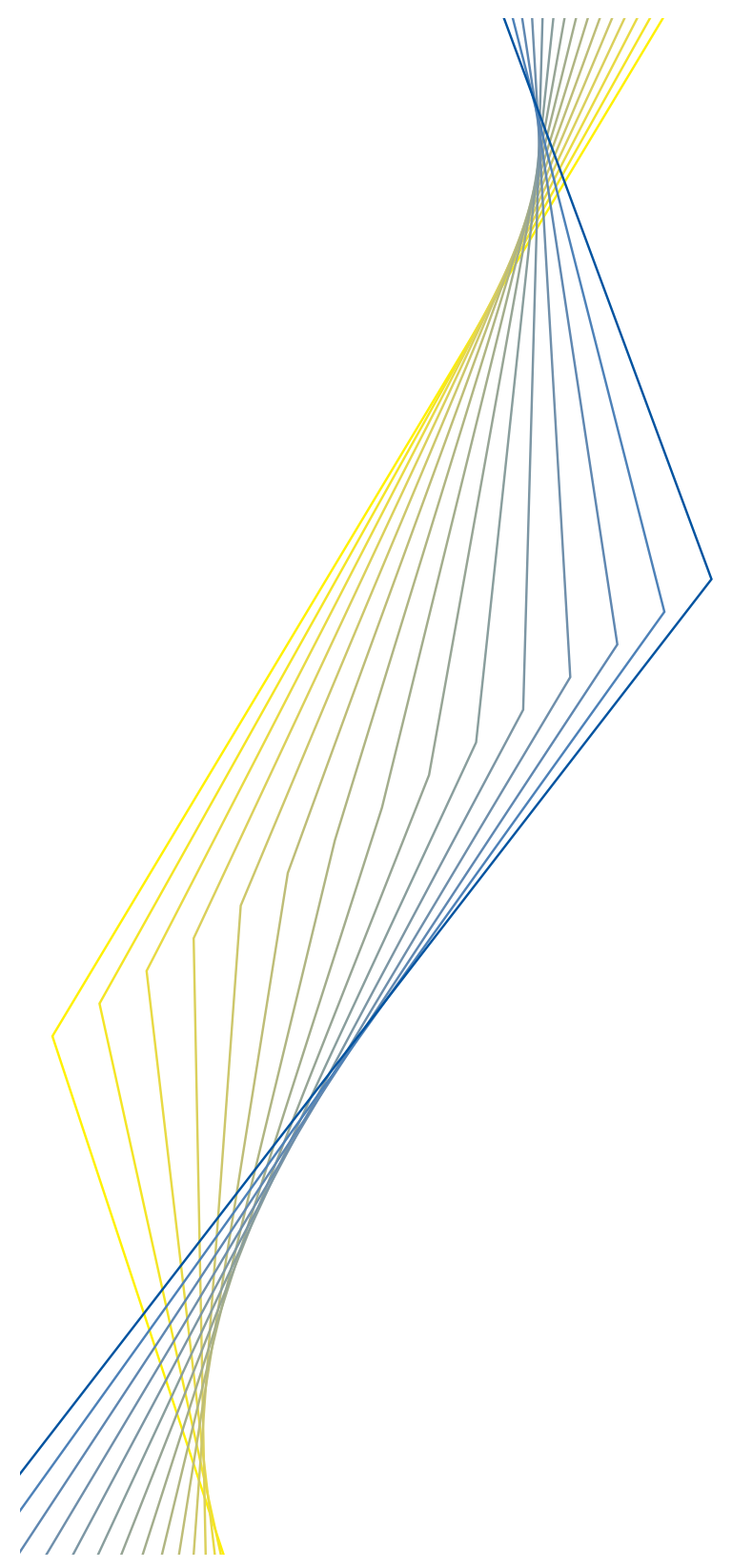

WORKING PAPER NO. 7 I

\section{ASSET MARKET LINKAGES IN CRISIS PERIODS*}

\section{BY P. HARTMANN**, S. STRAETMANS*** AND \\ C.G. DE VRIES****}

\section{July 200 I}

* We like to thank Huang Xin and Laurens de Haan for many helpful discussions. We also appreciated the comments we received from Jon Danielsson, John Duca, Barry Eichengreen, Charles Goodhart, Jean-Charles Rochet, Robert Shiller, Mark Watson, two anonymous referees and the participants of seminars at the London School of Economics, the $E C B$, the Fed Dallas, the Fed Richmond, the Fed New York as well as participants of the Center for Financial Studies conference on "Liquidity Risk: Rethinking Risk Management", the Fed Chicago conference on "Bank Structure and Competition" and the CEPR "European Summer Symposium in International Macroeconomics". The last author gratefully acknowledges the hospitality and the support of the research department at the ECB. Any views expressed are solely the views of the authors and do not necessarily reflect those of the ECB or the Eurosystem.

** Philipp Hartmann, European Central Bank and CEPR, DG Research, Kaiserstraße 29, 603 I I Frankfurt, Germany

E-mail address: philipp.hartmann@ecb.int.URL: http://www.ecb.int

*** Stefan Straetmans, Limburg Institute of Financial Economics (Life), Economics Faculty, Maastricht University, P.O. Box 6I 6, 6200 MD Maastricht, The Netherlands E-mail address: s.straetmans@berfin.unimaas.nl·URL:http://www.fdewb.unimaas.nl/finance/faculty/straetmans/

* Casper G. de Vries, Erasmus Universität Rotterdam, The Netherlands

E-mail address: cdevries@few.eur.nl.URL http://www.eur.nl/people/cdevries/ 
(C) European Central Bank, 200 I

Address

Kaiserstrasse 29

D-603 I I Frankfurt am Main

\section{Germany}

Postfach 160319

Postal address

D-60066 Frankfurt am Main

\section{Germany}

+496913440

http://www.ecb.int

+4969 13446000

4 I I I44 ecb d

All rights reserved.

Reproduction for educational and non-commercial purposes is permitted provided that the source is acknowledged.

The views expressed in this paper are those of the authors and do not necessarily reflect those of the European Central Bank. 


\section{Contents}

$\begin{array}{ll}\text { Abstract } & 4\end{array}$

Non-technical Summary $\quad 5$

$\begin{array}{ll}\text { I Introduction } & 7\end{array}$

2 International Shock Propagation 9

3 Extreme Linkages: Theory II

4 Extreme Linkages: Estimation $\quad$ I3

5 Extreme Linkages: Hypothesis Testing I5

6 Extreme Linkages: Results for G-5 Countries 17

6.I Extreme Returns in Stock and Bond Markets 18

6.2 Extreme Co-movements within and between Stock and Bond Markets 21

7 Conclusions 24

Annex I: Data Description 26

Annex 2: Testing Results on Tail Inequality 26

$\begin{array}{ll}\text { References } & 28\end{array}$

European Central Bank Working Paper Series 31 


\begin{abstract}
We characterize asset return linkages during periods of stress by an extremal dependence measure. Contrary to correlation analysis, this non-parametric measure is not predisposed towards the normal distribution and can account for non-linear relationships. Our estimates for the G-5 countries suggest that simultaneous crashes in stock markets are about two times more likely than in bond markets. Moreover, stock-bond contagion is about as frequent as flight to quality from stocks into bonds. Extreme cross-border linkages are surprisingly similar to national linkages, illustrating a potential downside to international financial integration.
\end{abstract}

Key words: Financial Crises, Systemic Risk, Contagion, Market Crashes, Flight to Quality, Bivariate Extreme Value Analysis, Extreme Co-movements

JEL classification: G1, F3, C49 


\section{NON-TECHNICAL SUMMARY}

Do different financial markets crash jointly or is the fall of one the gain to another market? The answer to this question is crucial for our view on the stability of international financial markets and any systemic risk related to these markets. With the increasing involvement of banks in securities trading, the more likely simultaneous market crashes the more in danger are even banks that hold prudently diversified trading portfolios. Destabilised banks could then also threaten the payment and settlement process. The number of markets affected by a crisis situation may also determine the severity of any real effects that might follow. Recent financial crises in emerging market economies have again drawn attention to these issues. Academics, market participants and policy makers frequently point to the perceived occurrence of contagion, witness terminology like the 'Asian flu', the 'Russian virus' or 'tequila effects'. Others highlight joint shocks and macroeconomic fluctuations, triggering simultaneous crises in several markets or countries.

The previous finance and international macro literature has focussed on contagion phenomena within the same asset class, mainly between different national stock markets around the 1987 crash and more recently between currency markets subject to fixed exchange rate regimes. Simple cross-country correlation analysis and simple pooled regressions were used or more sophisticated ARCHtype and limited dependent variable models. The present paper adds a new perspective to the linkages between asset markets in crisis periods, by studying co-movements between different types of assets and by using a novel methodology based on bivariate extreme value theory. Notably, linkages between stock and bond markets are examined, so that apart from contagion and joint crashes phenomena like 'flight-to-quality' (a crash in stock markets accompanied by a boom in government bond markets) can be addressed. Such cross-asset extreme linkages are important for the analysis of international financial stability, since they have a bearing on the overall ('systemic') reach contagion or joint crashes can have. In contrast to the focus on emerging market countries in the recent literature, emphasis is put on the main industrial countries, looking at weekly data for stock and bond index returns for the G-5 countries (France, Germany, Japan, United Kingdom and United States).

On the methodological side return linkages between asset markets in periods of stress are characterised by means of a measure from statistical extreme value analysis that captures the dependence structure of multivariate distributions far away from the center. It turns out that this limiting dependence measure can be described by a single function that exists upon existence of the multivariate extreme value distribution. In contrast to correlation-based approaches towards measuring market linkages, which are predisposed towards the normal distribution, the probability law of the joint return process can be left unspecified, since a non-parametric estimator for the limiting dependence function is used. From these non-parametric limiting dependence estimates measures for the expected number of joint market crashes (or alternatively for the probability of a joint crash) given that at least one market crashes are derived. Thus market 
linkages in periods of truly extreme volatility are measured directly in the economically relevant money metric and associated probabilities, and no detour via correlation is necessary. Also in contrast to correlation, these measures are able to capture non-linear dependencies that may be particularly relevant in crisis situations.

A first univariate result for the G-5 countries is that stock market crashes in the order of a $20 \%$ weekly loss and bond market crashes in the order of an $8 \%$ weekly loss are not prevalent, but nevertheless happen about once or twice per human lifetime respectively. Turning to the bivariate results, economically relevant and statistically significant market linkages in crisis periods are detected. It is found that G-5 stock markets experience a co-crash in about one out of five crashes. This number is lower for bond markets, and still less for a co-crash between a stock and a bond market. Nevertheless, compared to the probability of experiencing a market crash at all, the conditional likelihood that such a crisis reaches a certain breadth (a co-crash) is markedly higher. However, the flight-to-quality phenomenon is about as common as the co-crash of a bond and a stock market, highlighting some limits to the ('systemic') propagation of financial market crises within and between G-5 countries. Overall, in line with free capital flows and financial integration between industrial countries, national borders do not seem to matter very much. Cross-border crisis linkages are not weaker than domestic linkages. From the perspective of domestic financial stability this might sometimes be regarded as the bad downside of such integration, suggesting that the surveillance of financial market stability cannot stop at national borders. Generally, the frequency of crashes and co-crashes is much higher than a normal distribution based analysis would one lead to believe.

In relation to the widely reported experiences of contagion among emerging market economies during several recent financial crises in Latin America, Asia and Eastern Europe and subsequent calls for the reform of the international financial architecture, the results of this paper also raise the question whether such phenomena are more or less frequent and severe among the large industrial countries. In particular, following up on the $20 \%$ ballpark estimate for a cocrash between stock markets, given that for the US a crash happens only about once every 40 years and considering that bond market or cross-asset co-crashes tend to happen less frequently, one may conclude that a widespread securities market meltdown in the main industrialised countries happens much less than once every 200 years. Therefore, future research applying our tools to emerging market asset returns could shed light on the issue whether in the current efforts to reform the international financial architecture it might be advisable to differentiate between the various types of countries. 


\section{Introduction}

Do different financial markets crash jointly or is the fall of one the gain to another market? The answer to this question is crucial for our view on the stability of international financial markets and the systemic risk in these markets. The more markets crash simultaneously, the more in danger are even large banks that hold widely diversified trading portfolios, possibly also threatening the payment and settlement process. The number of markets affected by a crisis situation may also determine the severity of any real effects that might follow. Recent financial crises in emerging market economies have again drawn attention to these issues. Academics, market participants and policy makers frequently point to the perceived occurrence of contagion, witness terminology like the "Asian flu". Others highlight joint shocks and macroeconomic fluctuations, triggering simultaneous crises in several markets or countries.

The phenomenon of financial market crises spilling over to other countries was first systematically studied by Morgenstern (1959, chapter X). ${ }^{1}$ He examines the effects of 23 stock market panics on foreign markets and explicitly refers to the "statistical extremes" of the stock market movements. The more recent econometric literature uses correlation analysis, often based on ARCH-type models. This literature asks whether stock market co-movements become stronger during crashes compared to non-crash times. It also investigates the direction of international spill-overs. Representative articles of this literature are King and Wadwhani (1990); Hamao, Masulis and Ng (1990); Malliaris and Urrutia (1992); Lin, Engle and Ito (1994); Susmel and Engle (1994). There is also some empirical work on whether currency crises are contagious, notably in Eichengreen, Rose and Wyplosz (1996), Sachs, Tornell and Velasco (1996), Kaminsky and Reinhart (2000). However, we know of only one systematic study of international bond market spill-overs in volatile periods by Borio and McCauley (1996). ${ }^{2}$

The present paper adds a new perspective to the linkages between asset markets, by studying co-movements between different types of assets and by using a novel methodology. In contrast to the existing literature we do not only study the connection between, say, different stock markets during times of stress, but we explicitly focus on the linkages between stock and government bond markets. Thus apart from studying phenomena like contagion or joint crashes of stocks, we look into phenomena such as "flight-to-quality", by which we mean a

\footnotetext{
${ }^{1}$ We like to thank Charles Goodhart for having pointed us to this historical reference.

${ }^{2}$ For a comprehensive survey of the financial market crises and contagion literature, see De Bandt and Hartmann (2000, sections 3.2 and 4.2).
} 
crash in stock markets accompanied by a boom in government bond markets. Such cross-asset extreme linkages are important for the analysis of international financial stability, since they have a bearing on the overall or "systemic" reach that contagion or joint crashes can have. We are not aware of any other hard quantitative examination of the latter phenomenon in financial markets.

The methodological novelty is that we do not use a conditional correlation type of analysis. We directly measure and report the expected number of market crashes conditional on the event that at least one market crashes. Studies which rely on conditional correlation analysis usually do report the amount of correlation, but stop short of reporting the information that has more direct economic meaning. In our opinion, the correlation measure is only an intermediate step in obtaining a measure such as the likelihood of a crash spill-over. The conditional correlation, moreover, is strongly predisposed towards the multivariate normal distribution. As our empirical analysis below shows, however, the multivariate normal dramatically underestimates the frequency of extreme market spill-overs. Boyer, Gibson and Loretan (1997) demonstrate for the bivariate normal that the conditional correlation measure varies considerably with the conditioning sets. In addition, this variation can easily be shown to be different for different classes of multivariate distributions; worse, the conditional crash correlation can be zero even if there is a high spill-over probability. For all these reasons we do not regard the statistical concept of correlation as an unambiguous measure of the economic interdependency between markets during times of stress.

This paper instead characterizes the return linkages between asset markets in periods of crisis by a measure from statistical extreme value analysis that captures the dependence structure of multivariate distributions far away from the center. It turns out that this limiting dependence measure can be described by a single function that exists upon existence of the multivariate extreme value distribution. In contrast to correlation-based approaches towards measuring market linkages, the probability law of the joint return process can be left unspecified because we use non-parametric estimators for the limiting dependence function. From these non-parametric limiting dependence estimates we derive estimates for the expected number of market crashes (or the probability of a second crash) given that at least one market crashes. Thus market linkages in crisis periods are measured directly in the economically relevant money metric and associated probabilities, and we do not make the detour via correlations.

The methodology is then used to analyze the linkages within and between equity and bond markets in the G-5 industrial countries in 
times of market turmoil. ${ }^{3}$ Our results indicate non-negligible crossasset market linkages in times of stress. However, the strongest extreme linkages we find are between different national equity markets, while the flight-to-quality phenomenon is about as frequent as simultaneous crashes of stock and bond markets. Whereas single bond or stock market crashes are relatively rare events (nonetheless happening about once or twice a human lifetime), the conditional probabilities of having a crash (or boom) in a market given one occurred in another market are markedly higher. Interestingly, cross-border linkages are not weaker than domestic linkages. Whereas these results confirm that in the era of free capital flows and globalization surveillance of financial market stability cannot stop at national borders, they also suggest that there are some limits as to how widely phenomena like contagion can usually reach.

The paper is organized as follows. In the next section a simple economic framework is sketched within which financial market interdependence can be analyzed empirically. Section 3 discusses the concept of the non-parametric asymptotic tail dependence measure for extreme financial market co-movements. Sections 4 and 5 present the related estimation and testing techniques. Section 6 contains the results of the empirical analysis, detailing national cross-asset linkages, cross-border linkages within the same asset class and cross-border cross-asset linkages. Conclusions are drawn in section 7. Two annexes provide more detail on the data used and further testing results.

\section{International Shock Propagation}

We develop a simple model of linkages between international asset markets for the purpose of being able to interpret the empirical results. In contrast with recent advances in the theoretical analysis of e.g. bank contagion, there are surprisingly few theoretical attempts to explicitly model crisis linkages between different security markets. ${ }^{4}$ This may perhaps be explained by the fact that standard asset pricing models can be adopted for this purpose. Following this route, we take

\footnotetext{
${ }^{3}$ Related analyses for a single type of contract have recently been carried out on foreign exchange data by Straetmans (1998) and Starica (1999) and on major stock markets by Straetmans (2000) and Longin and Solnik (2000). For analyses of asset market co-movements using regime-switching volatility models, see Ramchand and Susmel (1998) and Domanski and Kremer (2000). For studies of regular non-crisis cross-asset interdependency, see e.g. Longin and Solnik (1995), Fleming, Kirby and Ostdiek (1998) or Bodart and Reding (1999).

${ }^{4}$ The published literature by the time of writing comprises King and Wadwhani (1990), Calvo and Mendoza (2000).
} 
Dumas' (1994) presentation of the International CAPM as our point of departure. According to the ICAPM expected logarithmic excess returns $X_{i t+1}$ on a portfolio of assets from market $i$ satisfy

$$
E_{t}\left[X_{i t+1}\right]=\beta_{i t} m_{i t},
$$

where $m_{i t}$ is the time $t$ expected return on the world market portfolio in local currency in excess of the local nominal risk free rate, and $\beta_{i t}$ is a weighted average of the local inflation risk premia and the local market risk premia (see Dumas, 1994, p. 12). A model for the actual returns consistent with the ICAPM reads

$$
X_{i t+1}=\beta_{i t} m_{i t}+U_{i t+1}, E_{t}\left[U_{i t+1}\right]=0,
$$

where the $U_{i t+1}$ are market $i$ idiosyncratic innovations.

Consider now two different asset markets $i$ and $j$, possibly located in two different currency areas

$$
\begin{aligned}
& X_{i t+1}=\beta_{i t} m_{i t}+U_{i t+1}, \\
& X_{j t+1}=\beta_{j t} m_{j t}+U_{j t+1} .
\end{aligned}
$$

Suppose $\rho_{t}\left(U_{i t+1}, U_{j t+1}\right)=0$, where the operator $\rho(.,$.$) is a measure$ for statistical dependence. ${ }^{5}$ In that case, a shock to the market $i$, i.e. $U_{i t+1}$, has no impact on the pricing in market $j$ at time $t+1$. But updates of expected returns on the world market portfolio, market uncertainty or changes in the dependency structure between the market portfolio return and local inflation rates or local portfolio returns, all do affect the returns on both markets. The systematic part of the ICAPM generates linkages between different local asset markets. Note that these linkages can be either positive or negative, depending on the sign of the risk factors. Thus flight-to-quality, whereby investors switch out of stock markets into bond markets when stocks are under pressure, can easily be generated by this model.

Apart from a simultaneous movement in all asset markets, due to changes in the systematic part of the ICAPM, sequential movements indicative of propagation and contagion are also of interest. For example, a time $t+1$ shock $U_{i t+1}$ spills over into market $j$ at time $t+2$ via $\beta_{j t+2}$ as the wealth weights in $\beta_{j}$ generally have to be adjusted following a shock in market $i$. More intricate spill-overs can be considered as well. Suppose for example that in contrast to atemporal dependencies, intertemporal linkages do exist, or that information about a change in a local risk premium or in the world expected excess return propagates through the market at differential speed due to information

\footnotetext{
${ }^{5}$ For the time being one can think of $\rho$ as a covariance or a correlation.
} 
asymmetries. In these cases $\rho_{t}\left(X_{i t+1}, X_{j t+k}\right), k \neq 1$, will generally be non-zero.

Measured asset returns are necessarily discrete. In this paper we measure asset returns on a weekly basis. As far as any market spillovers take place within a week, say $\rho_{t}\left(X_{i t+1}, X_{j t+1 / 2}\right) \neq 0$ and where the time length 1 refers to the period of a week, we cannot distinguish between contagion effects and macro shocks affecting both returns simultaneously. While outside the scope of the present paper, in future work we plan also to investigate the time structure of the linkages by studying $\rho_{t}\left(X_{i t+1}, X_{j t+k}\right)$ for $k>1$.

\section{Extreme Linkages: Theory}

Suppose one is interested in measuring the expected number of market crashes given that at least one market crashes (or booms, as in the flight-to-quality case). This measure reflects how many other markets are on average drawn down, when one market crashes. Consider the case of two markets with random returns $X$ and $Y$. Let $x$ and $y$ be the thresholds above which we speak of a market boom. To study market crashes we adopt the convention to take the negative of a return, so that we can study all extreme events in the first quadrant. Let $\kappa$ stand for the number of markets with extreme returns. Our extreme linkage indicator is the conditional expectation $E[\kappa \mid \kappa \geq 1]$. From elementary probability theory (starting from the standard definition of conditional probability) we have that

$$
\begin{gathered}
\frac{P\{X>x, Y \leq y\}+P\{X \leq x, Y>y\}+2 P\{X>x, Y>y\}}{1-P\{X \leq x, Y \leq y\}}= \\
E[\kappa \mid \kappa \geq 1]=\frac{P\{X>x\}+P\{Y>y\}}{1-P\{X \leq x, Y \leq y\}} .
\end{gathered}
$$

Note that $E[\kappa \mid \kappa \geq 1]=P\{\kappa=2 \mid \kappa \geq 1\}+1$, so that an alternative interpretation of our extreme linkage indicator is in terms of (1 plus) the conditional probability that both markets crash given that at least one market crashes.

The question is how $E[\kappa \mid \kappa \geq 1]$ can be calculated in practice. Within the framework of the multivariate normal distribution this would be a trivial exercise, since only the first two moments have to be estimated. In the introduction we argued, however, that the framework of the multivariate normal and the associated correlation structure may not be suitable for analyzing extreme linkages between asset markets. To be able to break away from very specific distributional assumptions, we 
investigate $E[\kappa \mid \kappa \geq 1]$ when the conditioning quantiles $x$ and $y$ become large. To this end, define the upper quantile functions for $X$ and $Y$ respectively as

$$
\begin{aligned}
& Q_{1}(t u)=\left(1-F_{1}\right)^{-1}(t u) \\
& Q_{2}(t v)=\left(1-F_{2}\right)^{-1}(t v),
\end{aligned}
$$

for some positive $u, v$ and $t$. Choose $u, v$ and $t$ such that $Q_{1}(t u)=x$ and $Q_{2}(t v)=y$.

Upon substituting the above inverse quantile expressions into (3.1), one obtains the following asymptotic equivalent for (3.1):

$$
\begin{gathered}
\lim _{t \rightarrow+0} E[\kappa \mid \kappa \geq 1]= \\
\lim _{t \rightarrow+0} \frac{t^{-1} P\left\{X>Q_{1}(t u)\right\}+t^{-1} P\left\{Y>Q_{2}(t v)\right\}}{t^{-1}\left(1-P\left\{X \leq Q_{1}(t u), Y \leq Q_{2}(t v)\right\}\right)}=\frac{u+v}{l(u, v)} .
\end{gathered}
$$

The limit function $l(u, v)$ is the so called Stable Tail Dependence Function $(S T D F)$ and was introduced by Huang (1992). Multivariate extreme value theory deals with existence conditions, properties and estimators for this function, see Huang (1992) or De Haan and De Ronde (1998). ${ }^{6}$ The curvature of $l(u, v)$ completely determines the dependency structure between $X$ and $Y$ in the tail area. Basic properties of $l(u, v)$ are the linear homogeneity and the inequality

$$
\max (u, v) \leq l(u, v) \leq u+v .
$$

Equality holds on the left hand side if $X$ and $Y$ are completely dependent in the tail area, while equality on the right hand side obtains if $X$ and $Y$ are independent in the tail area. Notice that the bivariate normal distribution with correlation $\rho \in(-1,1)$ has $l(u, v)=u+v$, even if $\rho \neq 0$. This will also be illustrated in the empirical parts below.

The STDF relates marginal and joint probabilities as follows. First define the excess probabilities $p_{1}=P\{X>x\}, p_{2}=P\{Y>y\}$ and $p_{12}=1-P\{X \leq x, Y \leq y\}$, for ease of reference. Exploiting the homogeneity property one can easily show that the bivariate excess probability $p_{12}$ and the marginal probabilities $p_{1}$ and $p_{2}$ are related via the $S T D F$. For sufficiently small $t>0$

$$
l(u, v) \approx t^{-1}\left(1-P\left\{X \leq Q_{1}(t u), Y \leq Q_{2}(t v)\right\}\right) .
$$

Choose $t u=p_{1}$ and $t v=p_{2}$, so that $l(u, v)=l\left(t^{-1} p_{1}, t^{-1} p_{2}\right)$. Use the linear homogeneity of the $S T D F$ to write $t l\left(t^{-1} p_{1}, t^{-1} p_{2}\right)=l\left(p_{1}, p_{2}\right)$.

\footnotetext{
${ }^{6}$ The limit function is guaranteed to exist if the joint distribution of $X$ and $Y$ is in the domain of attraction of a multivariate extreme value distribution.
} 
Hence, for small values of $p_{1}$ and $p_{2}$, approximately

$$
l\left(p_{1}, p_{2}\right) \approx p_{12} \text {. }
$$

Thus the joint probability $p_{12}$ only depends on the marginal probabilities $p_{1}$ and $p_{2}$ and the dependence function $l(.,$.$) . The linkage measure$ can now be simply expressed as

$$
E[\kappa \mid \kappa \geq 1]=\frac{p_{1}+p_{2}}{p_{12}} \approx \frac{p_{1}+p_{2}}{l\left(p_{1}, p_{2}\right)} .
$$

Assume for example that $p_{1}=p_{2}=p$. Then, approximately

$$
E[\kappa \mid \kappa \geq 1] \approx \frac{2 p}{l(p, p)}=\frac{2}{l(1,1)} .
$$

If both returns are completely dependent in the tails, i.e. $l(1,1)=$ $\max (1,1)$, then $E[\kappa \mid \kappa \geq 1] \approx 2$ and the markets co-crash with certainty. But without extreme co-movements in the two markets $E[\kappa \mid \kappa \geq 1] \approx 1$, since $l(1,1)=2$.

\section{Extreme Linkages: Estimation}

The conditional expectation (3.1) is estimated by a two-step estimation procedure. In the first step one estimates the marginal extreme quantile cum probability combinations $\left(p_{1}, p_{2}\right)$. In the second step one imputes these univariate probability estimates into an estimator for the tail dependence function $l(.,$.$) in order to obtain an estimator for p_{12}$, cf. (3.7). The estimation procedure therefore essentially exploits (3.6).

Univariate excess probability estimation uses the stylized fact that asset return distributions exhibit heavy tails. Loosely speaking, this implies that the excess probability as a function of the corresponding quantile can be approximately described by a power law. The defining characteristic of these distributions is the property of regular variation at infinity

$$
\lim _{q \rightarrow \infty} \frac{1-F(q x)}{1-F(q)}=x^{-\alpha}, x>0, \alpha>0 .
$$

From this property it directly follows that such distributions, like e.g. the Student-t, have bounded moments only up to $\alpha$, where $\alpha$ is known as the tail index. In contrast, distributions with exponentially decaying tails or with finite endpoints have all moments bounded. Univariate excess probabilities for fat tailed marginals can be estimated by using the semi-parametric probability estimator from De Haan et al. (1994):

$$
\widehat{p}_{q}=\frac{m}{n}\left(\frac{X_{n-m, n}}{q}\right)^{\alpha},
$$


where the "tail cut-off point" $X_{n-m, n}$ is the $(n-m)$-th ascending order statistic (or losely speaking the $m$-th smallest return) from a sample of size $n$ such that $\lim (1 / m(n))=0$, but $m=o(n)$, and where the extreme probability-quantile combination $\left(\widehat{p}_{q}, q\right)$ is such that $q>X_{n-m, n}$. (In financial risk management the scaling parameter $q$ is usually referred to as the "value at risk (VaR)", although it is often used in a reversed fashion: what is the $\operatorname{VaR} \widehat{q}_{p}$ for a given probability $p$ ?). An important aspect of the estimator $\widehat{p}_{q}$ is that it can extend the empirical distribution function outside the domain of the sample by means of its asymptotic Pareto tail from (4.1). The estimator (4.2) is conditional upon the tail index $\alpha$. We estimate the tail index by means of the popular Hill (1975) estimator:

$$
\widehat{\gamma}=1 / \widehat{\alpha}=\frac{1}{m} \sum_{j=0}^{m-1} \ln \left(\frac{X_{n-j, n}}{X_{n-m, n}}\right),
$$

where (as above) the nuisance parameter $m$ equals the number of highest order statistics used in the estimation and where $\widehat{\alpha}$ is the corresponding tail index estimate. Further details are provided in Jansen and De Vries (1991) and the recent monograph by Embrechts, Kliippelberg and Mikosch (1997).

The estimation of the bivariate excess probability $p_{12}$ either requires adopting a specific functional form for the $S T D F$, like in Longin and Solnik (2000), or proceeding non-parametrically. Since there does not exist a unique parametrization for the $S T D F$, we like to pursue a nonparametric estimation method based on the highest order statistics. Let $t=k / n$ in (3.5), such that $\lim (1 / k(n))=0$, while $k=o(n)$. (The role of the nuisance parameter $k$ corresponds to the one of $m$ in the univariate estimation step.) Since marginal probability estimates are available from the univariate step, we can also replace $(u, v)$ by $\left(\widehat{p}_{1}, \widehat{p}_{2}\right):^{7}$

$$
l\left(\widehat{p}_{1}, \widehat{p}_{2}\right)=\lim _{n \rightarrow \infty} \frac{n}{k} P\left\{X \geq Q_{1}\left(\frac{k \widehat{p}_{1}}{n}\right) \text { or } Y \geq Q_{2}\left(\frac{k \widehat{p}_{2}}{n}\right)\right\} .
$$

In order to turn this expression into an estimator for $l(.,$.$) , we replace$ $P, Q_{1}$ and $Q_{2}$ by their empirical counterparts, so that approximately:

$$
\widehat{l}\left(\widehat{p}_{1}, \widehat{p}_{2}\right) \approx \frac{n}{k} \frac{1}{n} \sum_{i=1}^{n} \mathbf{I}\left\{X_{i}>X_{n-\left[k \widehat{p}_{1}\right], n} \text { or } Y_{i}>Y_{n-\left[k \widehat{p}_{2}\right], n}\right\},
$$

\footnotetext{
${ }^{7}$ From elementary probability theory we know that $1-P\left\{X<Q_{1}, Y<Q_{2}\right\}=$ $P\left\{X \geq Q_{1}\right.$ or $\left.Y \geq Q_{2}\right\}$.
} 
where $[x]$ is the integer part of $x$. In practice we use Huang's (1992) polar transform of (4.5)

$$
\begin{aligned}
\widehat{p}_{12} & \approx \widehat{r} \widehat{l}(\cos \widehat{\theta}, \sin \widehat{\theta}) \\
& =\frac{1}{k} \widehat{r} \sum_{i=1}^{n} \mathbf{I}\left(X_{i}>X_{n-[k \cos \widehat{\theta}], n} \quad \text { or } Y_{i}>Y_{n-[k \sin \widehat{\theta}], n}\right)
\end{aligned}
$$

and where the angle $\theta$ and corresponding radius $r$ can be consistently estimated by

$$
\widehat{\theta}=\arctan \left(\widehat{p}_{2} / \widehat{p}_{1}\right) \text { and } \widehat{r}=\sqrt{\widehat{p}_{1}^{2}+\widehat{p}_{2}^{2}} .
$$

This estimator evaluates $l$ on the unit circle, which is convenient since it is based on a larger set of observations than (4.5). ${ }^{8}$

The entire estimation procedure thus depends on three estimators (4.2), (4.3), and (4.6) that are easy to calculate. Conditional on the proper choice of the nuisance parameters $m$ and $k$, the three estimators are asymptotically normally distributed. To determine $m$ and $k$, Goldie and Smith (1987) and Huang (1992) show that one picks $m$ and $k$ such that these are in the range which minimizes the respective asymptotic mean-squared errors. ${ }^{9}$ Consequently, minimizing the sample Mean Squared Error (MSE) is the appropriate selection criterion. In small samples best practice is to determine $m$ and $k$ by plotting the estimators as a function of the threshold, i.e., $\widehat{\gamma}=\widehat{\gamma}(m)$ and $\widehat{l}=\widehat{l}(k)$ and to select $m$ and $k$ in the region over which the estimators tend to be constant. ${ }^{10}$

\section{Extreme Linkages: Hypothesis Testing}

The asymptotic normality of the estimators above enables some straightforward hypothesis testing. A test for the equality of tail indices

\footnotetext{
${ }^{8}$ Since by choice $\widehat{p}_{i} \approx 1 / n$ or less, $k \widehat{p}_{i}$ is small and hence (4.5) is based on only a few observations. In (4.6) the linear homogeneity scales up $\widehat{l}$ by $1 / \widehat{r}$, to the effect that this increases the number of excess observations because $\cos \widehat{\theta}>\widehat{p}_{1}$ and $\sin \widehat{\theta}>$ $\widehat{p}_{2}$.

${ }^{9}$ There exists an intermediate range of thresholds for which bias-squared and variance vanish at the same rate, while outside this range one of the two parts dominates and the asymptotic MSE is higher.

${ }^{10}$ Plots are available upon request; see e.g. Embrechts et al. (1997) and De Haan and De Ronde (1998) for this widespread practice in small samples.
} 
can be based on the following $T$-statistic

$$
T_{12}=\frac{\widehat{\gamma}_{1}\left(m_{1}\right)-\widehat{\gamma}_{2}\left(m_{2}\right)}{\sigma\left[\widehat{\gamma}_{1}\left(m_{1}\right)-\widehat{\gamma}_{2}\left(m_{2}\right)\right]},
$$

and where the asymptotic standard error $\sigma[$.$] is obtained via a boot-$ strap estimate of the variance and covariance terms. The number of bootstrap replications is set equal to 600 .

For several multivariate distributions, like the multivariate normal distribution, all dependency disappears in the tail area, and the contour lines of the STDF are linear, recall (3.4). Other multivariate distributions exhibit dependency in the tail area, which is then captured by the $S T D F$ that displays strictly concave contour lines. Before quantifying the magnitude of any extreme linkages, we pretest with Peng's (1999) test for asymptotic dependence whether any statistically significant ones actually exist. To introduce this test, consider the following general second order expansion for the excess probability

$$
P\left\{X>Q_{1}, Y>Q_{2}\right\}=c(u, v) t^{1 / \eta}\left[1+O\left(t^{\beta}\right)\right],
$$

where $\beta, t>0$ and $t$ sufficiently small. Quantiles $Q_{1}$ and $Q_{2}$ are defined as in (3.2). From elementary probability theory we know that the LHS probability in (5.2) boils down to

$$
P\left\{X>Q_{1}\right\}+P\left\{Y>Q_{2}\right\}-P\left\{X>Q_{1} \text { or } Y>Q_{2}\right\} .
$$

Using (3.2) and (3.3) this approximately equals:

$$
t u+t v-t l(u, v)
$$

Substitute this result into (5.2) to obtain

$$
u+v-l(u, v) \approx c(u, v) t^{(1-\eta) / \eta} .
$$

The value of the tail dependence coefficient $\eta$ governs whether extremal returns are asymptotically independent or not. If $X$ and $Y$ are asymptotically independent we already know that $l(u, v)=u+v$. Thus necessarily $\eta<1$ in (5.3) as $t \rightarrow 0$. The case of asymptotic dependence corresponds to $\eta=1$, so that both sides do not vanish when $t \rightarrow 0$. Still following Peng (1999) a consistent and asymptotically normal estimator for the tail dependence coefficient $\eta$ is then given by

$$
\widehat{\eta}=\frac{\ln 2}{\ln [4-\widehat{l}(2,2)]-\ln [2-\widehat{l}(1,1)]} .
$$

The motivation for $\widehat{\eta}$ can be easily seen from (5.3). The asymptotic normality of $\widehat{\eta}$ allows one to test for $\mathrm{H}_{0}: \eta=1$ against $\mathrm{H}_{1}: \eta<1$ by 
means of the test statistic

$$
W=\frac{\widehat{\eta}-1}{\sigma(\widehat{\eta})}
$$

which is asymptotically normally distributed under $\mathrm{H}_{0} \cdot{ }^{11}$

Once we know there is asymptotic dependency, we can test for its importance. The asymptotic normality of the estimator (4.6) can be used to compare the amount of extreme dependence across different return quadrants. For a pair of stock and bond markets we can test whether contagion dominates flight-to-quality or vice versa by calculating the following $Z$-statistic:

$$
Z=\frac{\widehat{l}_{C O}\left(k_{1}\right)-\widehat{l}_{F T Q}\left(k_{2}\right)}{\sigma\left[\widehat{l}_{C O}\left(k_{1}\right)-\widehat{l}_{F T Q}\left(k_{2}\right)\right]},
$$

which has a standard normal distribution in large samples. ${ }^{12}$ In (5.6) the subscripts $C O$ and $F T Q$ to the $S T D F$ estimates refer to stock and bond co-crashes or stock crashes and resulting bond market booms (flight to quality), respectively.

\section{Extreme Linkages: Results for G-5 Countries}

In this section we evaluate the extent of extreme co-movements within and between stock and bond markets. The data consist of 623 weekly stock and government bond returns for the G-5 market indices over the period 1987 to $1999 .^{13}$ The stock and bond returns are not compensated for dividends and coupon payments, respectively. ${ }^{14} \mathrm{We}$

\footnotetext{
${ }^{11}$ The asymptotic standard error can be expressed in terms of the tail dependence function and its derivatives, see Peng (1999).

${ }^{12}$ For the sake of convenience, the tail dependence function is evaluated in $(1,1)$ along the 45 degree line. The asymptotic standard error is estimated by a bootstrap of the variance and covariance terms. The number of bootstrap replications is set equal to 600 .

${ }^{13}$ Data were obtained from Datastream, Inc. G-5 countries are listed with the following abbreviations: France (FR), Germany (GE), United Kingdom (UK), United States (US), Japan (JP). The stock data are Financial Times/Standard \& Poors world price indices, whereas the bond data correspond to price indices on 10 year ('all-traded') government bonds. We did not include corporate bond indices, because of our particular interest in the "flight-to-quality" phenomenon. Returns were calculated as log price differences, Friday to Friday, in local currency. The sample of daily raw data used started on 27 February 1999 and ended on 18 November 1999. Further information on the data are given in Annex 1.

${ }^{14}$ Weekly data have the advantage that one significantly reduces the typical time zone problems encountered with international data at the daily frequency. Moreover, they capture more sustained crash phenomena than one would usually pick up with daily returns, which can be expected to have more significant effects
} 
start with the univariate stock and bond market extremes, eye-balling first indications for their joint occurrence. Then we turn to the systematic application of our extreme linkage measure.

6.1. Extreme Returns in Stock and Bond Markets. In the univariate step, we report tail index and quantile-probability estimates on the basis of (4.3) and (4.2). Table 1 contains information on the magnitude and timing of the most extreme in-sample events for stocks (panel A) and bonds (panel B). The table also gives the estimates of the tail index $\alpha$ and the number of higher order statistics $m$ which are used in computing the Hill estimator (4.3). We distinguish between the upper and lower tails of the univariate return distributions.

TABle 1. Minima, maxima and tail index estimates for weekly G-5 asset returns, 1987 to 1999

\begin{tabular}{|c|c|c|c|c|c|c|}
\hline Country & $\begin{array}{l}\min \% \\
\text { (Date) }\end{array}$ & $\begin{array}{l}\max \% \\
\text { (Date) }\end{array}$ & $m_{L}$ & $m_{R}$ & $\widehat{\alpha}_{L}$ & $\widehat{\alpha}_{R}$ \\
\hline & \multicolumn{6}{|c|}{ Panel A: Stocks } \\
\hline$\overline{\mathrm{GE}}$ & $\begin{array}{l}-13.81 \\
(2 / 10 / 98)\end{array}$ & $\begin{array}{l}11.57 \\
(16 / 10 / 98)\end{array}$ & 10 & 15 & 3.32 & 4.68 \\
\hline FR & $\begin{array}{l}-11.12 \\
(23 / 10 / 87)\end{array}$ & $\begin{array}{l}9.61 \\
(16 / 10 / 98)\end{array}$ & 30 & 40 & 3.24 & 5.68 \\
\hline UK & $\begin{array}{l}-24.83 \\
(23 / 10 / 87)\end{array}$ & $\begin{array}{l}8.19 \\
(18 / 9 / 92)\end{array}$ & 20 & 20 & 3.76 & 4.54 \\
\hline US & $\begin{array}{l}-13.60 \\
(23 / 10 / 87)\end{array}$ & $\begin{array}{l}7.25 \\
(16 / 10 / 98)\end{array}$ & 40 & 20 & 2.33 & 5.56 \\
\hline \multirow[t]{2}{*}{ JP } & $\begin{array}{l}-13.32 \\
(23 / 10 / 87)\end{array}$ & $\begin{array}{l}11.18 \\
(21 / 8 / 92)\end{array}$ & 30 & 10 & 3.07 & 4.61 \\
\hline & \multicolumn{6}{|c|}{ Panel B: Bonds } \\
\hline GE & $\begin{array}{l}-6.61 \\
(30 / 12 / 94)\end{array}$ & $\begin{array}{l}3.77 \\
(9 / 1 / 98)\end{array}$ & 10 & 10 & 5.39 & 5.57 \\
\hline FR & $\begin{array}{l}-5.14 \\
(28 / 10 / 94)\end{array}$ & $\begin{array}{l}5.21 \\
(23 / 10 / 87)\end{array}$ & 10 & 10 & 6.01 & 5.58 \\
\hline UK & $\begin{array}{l}-6.35 \\
(9 / 10 / 98)\end{array}$ & $\begin{array}{l}4.81 \\
(10 / 4 / 92)\end{array}$ & 10 & 20 & 3.91 & 4.46 \\
\hline US & $\begin{array}{l}-5.41 \\
(15 / 5 / 87)\end{array}$ & $\begin{array}{l}9.77 \\
(23 / 10 / 87)\end{array}$ & 50 & 50 & 3.45 & 3.72 \\
\hline JP & $\begin{array}{l}-5.08 \\
(25 / 12 / 98)\end{array}$ & $\begin{array}{l}4.30 \\
(6 / 11 / 87)\end{array}$ & 10 & 30 & 4.58 & 2.84 \\
\hline
\end{tabular}

on financial institutions and the real economy. An even longer holding period was not possible due to the limited length of the bond index data available to us. Of course, the two advantages of the use of weekly data mentioned above come at the cost of not being able to address explicitly intra-day or daily short-run dynamics that could also help to understand crisis propagation mechanisms. 
Focussing on the first two columns in Table 1, we see that the extremal stock index loss returns are generally much higher than extremal bond index returns. The historical extremes point towards asymmetries in stock index returns: The extreme loss returns consistently exceed the maximal positive returns. ${ }^{15}$ When comparing the entries for stock and bond markets, the timing of the extreme events, as recorded between brackets, suggests the presence of co-crashes and flight-to-quality effects during periods of market turbulence. Indeed all stock markets covered, except for Germany, reached historically low returns in the week of Black Monday. As an aside, the Table also shows that 3 stock markets (FR, GE, US) exhibited parallel record gains as a consequence of a major rebounce in mid October 1998 following the Russian and LTCM crises (in all likelihood related to the US Fed's emergency interest rate reductions around this period) and 2 stock markets (JP, UK) exhibited comparable record gains around the September 1992 European currency crisis. The casual extreme linkage evidence is less clear for bond markets. For example, non of the largest bond index corrections occurred during the February to June 1994 fixed income market turmoil and only the UK experienced a record slump in the aftermath of the LTCM crisis. The October 1987 rallies in the French and US bond markets (and perhaps also the Japanese rally two weeks later) are suggestive for a flight-to-quality effect from stocks into government bonds.

We turn to the remaining columns in Table 1. The left tail parameters are highest for the bond returns indicating thinner lower tails in comparison with the stocks. This reflects the more limited downside risk of bond investments. Moreover, and in contrast to the bond series, the point estimates $\widehat{\alpha}$ for the left tail of the stock index series are lower than their right tail counterparts, which is consistent with the observed asymmetry between the minimal and maximal stock returns reported in the left part of the table. Using the $T$ - test as defined in (5.1) we formally tested for equality of tail indexes across lower and upper tails and across assets. It turned out that only in the French and US stock markets the larger size of left tails are actually statistically significant. And again, only in France the left stock market tail is significantly

\footnotetext{
${ }^{15}$ On Friday, October 16, 1987 the UK stock market remained closed due to a hurricane. Therefore, the weekly return in the UK for the period around Black Monday is calculated from Thursday to Friday, not from Friday to Friday. As a result the figure of a $25 \%$ fall (much higher than for the four other countries) might somewhat overstate the London crash in relative terms.
} 
thicker than the left bond market tail. In almost all other cases the null hypothesis of equal tail indexes could not be rejected. ${ }^{16}$

TABLE 2. Univariate tail probabilities for weekly G-5 asset returns

\begin{tabular}{llll|lll}
\hline \hline Country & \multicolumn{5}{c}{ Panel A: Stocks } \\
\hline return & \multicolumn{7}{c}{ Left tail } & \multicolumn{1}{l}{ Righ tail } \\
\hline GE & $-10 \%$ & $-20 \%$ & $-30 \%$ & $10 \%$ & $20 \%$ & $30 \%$ \\
FR & 0.19306 & 0.01926 & 0.00500 & 0.03942 & 0.00153 & 0.00023 \\
UK & 0.05190 & 0.01308 & 0.00355 & 0.02021 & 0.00039 & 0.00004 \\
US & 0.12908 & 0.02559 & 0.00993 & 0.00822 & 0.00017 & 0.00002 \\
JP & 0.18507 & 0.02209 & 0.00637 & 0.09701 & 0.00397 & 0.00061 \\
\hline \multicolumn{7}{c}{ Panel B: Bonds } \\
\hline return & $-6 \%$ & $-8 \%$ & $-10 \%$ & $6 \%$ & $8 \%$ & $10 \%$ \\
\hline GE & 0.06564 & 0.01393 & 0.00419 & 0.00749 & 0.00151 & 0.00044 \\
FR & 0.03202 & 0.00568 & 0.00148 & 0.00568 & 0.00114 & 0.00033 \\
UK & 0.03412 & 0.01109 & 0.00464 & 0.02771 & 0.00767 & 0.00284 \\
US & 0.08996 & 0.03301 & 0.01540 & 0.04323 & 0.01480 & 0.00646 \\
JP & 0.03497 & 0.00936 & 0.00337 & 0.05164 & 0.02277 & 0.01207 \\
\hline \hline
\end{tabular}

The economic issue of interest is the likelihood of the extreme returns. This question is addressed in Table 2 for stocks (Panel A) and bonds (Panel B). The excess probabilities are conditioned on different quantiles for the stocks and bonds with an eye towards the previous table's historical minima and maxima. The reported probabilities are expressed over a yearly time horizon by multiplying the weekly probability estimates from (4.2) with a factor of 52. Thus the entry 0.02559 for the US in Table 2-Panel A in the column with the probability estimates at the $20 \%$ loss level implies, that once per $1 / 0.02559 \approx 39$ years there is a year in which the stock market drops by more than $20 \%$ over the course of a single week. In other words, such crashes are rare events but not so uncommon as one might believe. They happen about twice per human lifetime. (In bond markets a $10 \%$ decline would occur about once per lifetime.) Compare these estimates to a normal distribution based estimate, which would predict co-crashes in common stock to happen only once per $31.5 \times 10^{20}$ years; this implies a factor difference of order $10^{20} !^{17}$ Given the persisting popularity of

\footnotetext{
${ }^{16}$ The detailed results of these tests are reported in Annex 2. This annex also reports further tests of relative tail thickness across countries and across asset types.

${ }^{17}$ As for the $10 \%$ level, Table 2 suggests a weekly crash of this magnitude in the US market once every $1 / 0.12908=7.7$ years whereas a normal parametrization would suggest this to happen only once every 96799 years.
} 
the normality assumption, it should not surprise that agents tend to underestimate the probability of a financial crisis (see e.g. Friedman and Laibson, 1989).

\subsection{Extreme Co-movements within and between Stock and}

Bond Markets. In the bivariate step we first pre-test for the presence of extreme linkages by means of the $W$-test from (5.5) prior to quantifying their magnitude. Subsequently we calculate the conditional expected number of market crashes (3.7) for the market pairs with significant asymptotic dependence. In the same way we calculate the expected number of simultaneous busts and booms for pairs of negative stock returns and positive bond returns. For curiosity we also report the standard correlation coefficient. Finally we examine by means of the $Z$-test from (5.6) whether co-crashes or flight-to-quality between stock and bond markets are equally likely to happen. We focus first on the extreme linkages within the stock market asset class and within the bond market asset class. We then study the extreme linkages between these two asset classes.

TABLE 3. Cross-border extreme linkages within bond and stock markets

\begin{tabular}{lrcc|ccl}
\hline \hline \multicolumn{4}{c}{ Stocks $^{1}$} \\
\hline Pairs & $W_{C O}^{S S}$ & $\rho$ & $E_{C O}^{S S}$ & $W_{C O}^{B B}$ & $\rho$ & $E_{C O}^{B B}$ \\
\hline GE-FR & 0.601 & 0.686 & 1.263 & -0.251 & 0.600 & 1.164 \\
GE-UK & -0.457 & 0.575 & 1.130 & -0.859 & 0.438 & 1.109 \\
GE-US & -1.206 & 0.470 & 1.148 & -0.466 & 0.291 & 1.090 \\
GE-JP & -0.437 & 0.314 & 1.216 & -1.307 & 0.198 & 1.051 \\
FR-UK & -1.131 & 0.589 & 1.208 & -0.758 & 0.491 & 1.085 \\
FR-US & -1.156 & 0.497 & 1.201 & -1.059 & 0.363 & 1.049 \\
FR-JP & -1.159 & 0.322 & 1.142 & -0.691 & 0.129 & 1.023 \\
UK-US & -1.404 & 0.546 & 1.118 & -0.512 & 0.425 & 1.100 \\
UK-JP & -1.370 & 0.361 & 1.057 & -1.340 & 0.184 & 1.104 \\
US-JP & -0.888 & 0.328 & 1.119 & -0.876 & 0.164 & 1.080 \\
\hline${ }^{1} E_{C O}^{S S}:=\frac{P\left\{S_{1}<-s_{1}\right\}+P\left\{S_{2}<-s_{2}\right\}}{P\left\{S_{1}<-s_{1} \text { or } S_{2}<-s_{2}\right\}}$ & ${ }^{2} E_{C O}^{B B}:=\frac{P\left\{B_{1}<-b_{1}\right\}+P\left\{B_{2}<-b_{2}\right\}}{P\left\{1 B_{1}<-b_{1} \text { or } B_{2}<-b_{2}\right\}}$ \\
\hline \multicolumn{4}{c}{$\left(s_{1}, s_{2}\right)=(20 \%, 20 \%)$} & $\left(b_{1}, b_{2}\right)=(8 \%, 8 \%)$ \\
\hline \hline
\end{tabular}

Table 3 reports extreme linkage results within the same asset class across borders. For both stocks and bonds the $W$-test never rejects the null of asymptotic dependence at the 5\%-significance level. The third and sixth column report our extreme linkage measure (3.7). For stocks the conditional expectation is conditioned on the $20 \%$ loss quantile, whereas for bonds we chose the $8 \%$ loss quantile. Extreme cross-border linkages at the lower tail are stronger within stock markets than within 
bond markets. Roughly one out of five stock market crashes is a cocrash. In the bond markets this number is less than one out of ten. This is consistent with a higher propensity for contagion or co-crashes between stock markets than between bond markets. Compared to the likelihood of single crashes, the probability of having a crash given a crash elsewhere are surprisingly high. In other words, while severe financial market crises as such are fairly rare events, they can become easily more widespread once they strike. However, as we will see further below, there exist also some limits to how far they tend to reach. With the exception of the Continental European country pair GE-FR, which exhibits the most highly interlinked stock and bond markets, no clear geographical patterns of crisis linkages can be discerned.

Note that the simple correlation measure (for the full distribution) reported in Table 3 might be easily read as suggesting even higher linkages, but this is rather an illusion. Indeed, suppose one applied the multivariate normal distribution in order to assess the stock-stock and bond-bond market linkages between e.g. France and Germany. We would find that $E_{C O}^{S S}$ and $E_{C O}^{B B}$ are equal to 1.000 joint stock crashes of at least $20 \%$ and 1.0006 joint bond crashes of at least $8 \%$, respectively. Only if we condition on the $10 \%$ loss level for stocks we find evidence for co-dependence under the normal (one out of 25 mini-crashes is expected to be a co-crash under the normal parametrization). Hence, in spite of fairly high correlation coefficients the multivariate normal massively underrates extreme financial market linkages!

Table 4 contains the results on extreme linkages across asset classes. The upper part of the Table gives the results for extreme stock-bond market linkages within a given country, the lower part details international stock-bond market linkages (situating the stock market in the first country mentioned and the bond market in the second country). The $W$-test from (5.5) cannot reject asymptotic dependence for most asset market pairs, as shown for the case of co-crashes by the $W_{C O}^{S B}$ statistic and for the case of flight-to-quality from stocks into bonds by the $W_{F T Q}$ statistic. Only for the GE-FR pair in row 6 is the hypothesis of asymptotic co-crashes between German stocks and French bonds rejected at the $5 \%$ level (but not for French stocks and German bonds). In other words, our data display a significant degree of interdependence among G-5 financial markets during periods of crisis, well illustrating the relevance of the channels discussed in Section 2 by means of the ICAPM.

Given that there is both asymptotic dependence between the losses on stocks and bonds and between stock losses and gains in the bond markets, it is of some interest to test for the equality of the two effects. 
TABle 4. Domestic and international extreme crossasset linkages: co-crash versus flight-to-quality

\begin{tabular}{|c|c|c|c|c|c|c|}
\hline & \multicolumn{3}{|c|}{ Test Statistics } & \multicolumn{3}{|c|}{ Linkage Estimates $^{1,2}$} \\
\hline & $W_{C O}^{S B}$ & $W_{F T Q}^{S B}$ & $Z$ & $\rho$ & $E_{C O}^{S B}$ & $E_{F T Q}^{S B}$ \\
\hline Country & \multicolumn{6}{|c|}{ Panel A: Domestic } \\
\hline $\mathrm{GE}$ & -0.881 & -0.265 & 0.311 & 0.190 & 1.027 & 1.034 \\
\hline FR & -0.906 & -0.974 & -1.753 & 0.248 & 1.115 & 1.053 \\
\hline UK & -0.740 & -0.463 & $-3.992^{*}$ & 0.217 & 1.059 & 1.073 \\
\hline US & -0.658 & -0.906 & -0.432 & 0.235 & 1.052 & 1.043 \\
\hline JP & -0.719 & -1.376 & 0.099 & 0.051 & 1.092 & 1.040 \\
\hline Pairs $(S-B)$ & \multicolumn{6}{|c|}{ Panel B: Cross-border } \\
\hline GE-FR & $-2.452^{*}$ & -0.681 & - & 0.187 & 1 & 1 \\
\hline FR-GE & 0.468 & -0.534 & -0.310 & 0.172 & 1.039 & 1.039 \\
\hline GE-UK & -1.271 & -1.031 & 0 & 0.079 & 1.078 & 1.059 \\
\hline UK-GE & -0.362 & -0.437 & 0.810 & 0.083 & 1.053 & 1.052 \\
\hline GE-US & -1.445 & -0.314 & -0.914 & 0.015 & 1.035 & 1.079 \\
\hline US-GE & -0.490 & 0 & 0.600 & 0.122 & 1.060 & 1.057 \\
\hline GE-JP & -0.450 & -0.416 & 0.277 & -0.056 & 1.096 & 1.068 \\
\hline JP-GE & -0.413 & -0.861 & 0.683 & -0.000 & 1.014 & 1.031 \\
\hline FR-UK & -1.107 & 0 & -0.367 & 0.165 & 1.052 & 1.080 \\
\hline UK-FR & -1.013 & -0.269 & -0.874 & 0.102 & 1.068 & 1.051 \\
\hline FR-US & -0.473 & -1.459 & 0.831 & 0.101 & 1.080 & 1.077 \\
\hline US-FR & -0.795 & -0.939 & 0.718 & 0.097 & 1.028 & 1.030 \\
\hline FR-JP & -0.498 & -0.891 & 1 & -0.007 & 1.041 & 1.083 \\
\hline JP-FR & -1.269 & -1.334 & -0.467 & 0.021 & 1.038 & 1.036 \\
\hline UK-US & -0.681 & -0.285 & 0.663 & -0.055 & 1.025 & 1.083 \\
\hline US-UK & -0.456 & -0.721 & 1.267 & 0.141 & 1.038 & 1.052 \\
\hline UK-JP & -0.855 & -0.270 & 0.778 & -0.015 & 1.016 & 1.080 \\
\hline JP-UK & -0.706 & -0.640 & -0.925 & 0.042 & 1.049 & 1.032 \\
\hline US-JP & -0.244 & -0.744 & 0.516 & 0.068 & 1.069 & 1.080 \\
\hline JP-US & -1.426 & -0.496 & $-2.118^{*}$ & -0.011 & 1.050 & 1.033 \\
\hline \multicolumn{4}{|c|}{${ }^{1} E_{C O}^{S B}:=\frac{P\{S<-s\}+P\{B<-b\}}{P\{S<-s \text { or } B<-b\}}$} & \multicolumn{3}{|c|}{${ }^{2} E_{F T Q}:=\frac{P\{S<-s\}+P\{B>b\}}{P\{S<-s \text { or } B>b\}}$} \\
\hline \multicolumn{4}{|c|}{$(s, b)=(20 \%, 8 \%)$} & \multicolumn{3}{|c|}{$(s, b)=(20 \%, 8 \%)$} \\
\hline
\end{tabular}

The question is whether joint crashes or contagion are more pervasive than flight-to-quality, given that a crash has occurred. This question is answered with the $Z$-test from (5.6); see Table 4 , third column. ${ }^{18}$ It turns out that co-crashes dominate flight-to-quality in only two of the cases at the $1 \%$ significance level. For all other countries and market pairs the two effects are not significantly different from each other. On the other hand, the stock-bond correlations in Table 4 are in most cases positive, which would suggest that co-crashes dominate flight-toquality phenomena. This apparent difference between correlations and

\footnotetext{
${ }^{18}$ The equality test for the GE-FR pair is deleted form Table 4 because its limit distribution is degenerate under asymptotic independence.
} 
our semi-parametric extreme events approach illustrates that simple full sample - correlations are unreliable as indicators for the direction of extreme co-movements. One interpretation of these results on extreme cross-asset linkages is that there are some non-negligible barriers to how far contagious financial market crashes can reach.

The last two columns report the conditional expected number of extreme market movements measure from (3.7). The expected values for co-crashes and flight-to-quality phenomena are comparable in magnitude, i.e. $E_{F T Q} \approx E_{C O}^{S B}$, which is in line with the $Z$-tests. In comparison with the previous table we see that the linkage measures across different assets tends to be lower than those for linkages across bond markets, so that roughly the following ordering emanates from the data: $E_{C O}^{S S}>E_{C O}^{B B}>E_{C O}^{S B}$. This inequality confirms then that stocks constitute a more risky asset class than government bonds and that cross-asset crashes are relatively less likely than within-asset crashes.

The patterns for cross-border linkages in Table 4 are surprisingly similar to within-country linkages. National borders do not seem to limit the degree of contagion or flight-to-quality, which illustrates well a potential disadvantage of international financial market integration from the perspective of domestic financial market stability. Also, it is very hard to disentangle any geographical patterns, e.g. related to distance, say stronger cross-asset linkages between European countries. There is rather some evidence of "safe haven" behaviour, since in the last column the numbers for $E_{F T Q}$ of the cross border pairs are in many cases slightly above the local market numbers in the top part of the table. In particular, by comparing the country pairs involving the US one can see that the probability of experiencing a rally in US government bonds, given a stock market crash elsewhere, is almost always among the highest (with the exception of US-JP). This may well show the historical role of the dollar and US government securities as a "safe haven" for European investors.

\section{Conclusions}

The linkages between asset markets in periods of crisis are characterized by their asymptotic tail dependence. From this measure we derive non-parametric estimates for the expected number of market crashes given that at least one market crashes. This novel approach does not rely on a specific probability law for the returns, and therefore has the distinct advantage over the often used conditional correlation measure, that it cannot distort the view on the extreme spill-over likelihood. 
Thus the approach in this paper bypasses the indirect method of computing a correlation and subsequently inferring the probability of loss, by directly calculating the economically relevant measure.

A first result for the G-5 countries from the univariate analysis is that stock market crashes in the order of a $20 \%$ weekly loss and bond market crashes in the order of an $8 \%$ weekly loss are not prevalent, but nevertheless do happen once or twice per lifetime. Turning to the bivariate results, we found that stock markets realize a co-crash in about one out of five crashes. This number is lower for bond markets, and still less for a co-crash between a stock and a bond market. Nevertheless, compared to the probability of experiencing a market crisis at all, the conditional likelihood that such a crisis reaches a certain breadth (a co-crash) is markedly higher. However, the flight-to-quality phenomenon is about as common as the co-crash of a bond and a stock market, highlighting some limits to the propagation of financial market crises. Overall, in line with free capital flows and financial integration between G-5 countries, national borders do not seem to matter very much. From the perspective of domestic financial stability this might sometimes be regarded as the bad downside of such integration, suggesting that the surveillance of financial market stability cannot stop at national borders. Generally, the frequency of crashes and the occurrence of co-crashes is much higher than a normal distribution based analysis would one lead to believe.

In relation to the widely reported experiences of contagion among emerging market economies during several recent financial crises in Latin America, Asia and Eastern Europe and subsequent calls for the reform of the international financial architecture, the results of this paper also raise the question whether such phenomena are more or less frequent and severe among the large industrial countries. In particular, following up on the $20 \%$ ballpark estimate for a co-crash between stock markets, given that for the US a crash happens only about once every 40 years and considering that bond market or cross-asset co-crashes tend to happen less frequently, one may conclude that a widespread securities market meltdown in the main industrialised countries happens much less than once every 200 years. Therefore, future research applying our tools to emerging market asset returns could shed light on the issue whether in the current efforts to reform the international financial architecture it might be advisable to differentiate between the various types of countries. 


\section{Annex 1: Data Description}

All the data used in this paper come from Datastream, Inc. ${ }^{19}$ Weekly returns are calculated from daily price indices, as weekly log first differences from Friday to Friday. The price indices do not include any corrections for dividend or coupon payments and are calculated from prices in local currency. The sample starts on 27 February and ends on 18 November 1999, which gives 623 weekly (non-overlapping) returns.

The raw daily stock market indices are Financial Times/Standard \& Poors world price indices. They are calculated at local market closing times, usually between $4 \mathrm{pm}$ and $5 \mathrm{pm}$. These indices are broad measures for price developments in the respective market, covering a representative list of individual stocks chosen according to market value and data availability (the largest value stocks are always included in the index). The number of stocks included is determined in relation to the total market capitalization in a country.

The raw daily bond market indices are 10 year "all-traded" government bond indices. They are calculated for all markets between 4.30am and 5am Greenwich Mean Time (GMT). In comparison to "benchmark" indices, the "all-traded" category includes a broader range of issues (liquid and illiquid ones) in order to encompass the entire sector for the given maturity.

\section{Annex 2: Testing Results on Tail Inequality}

In this annex we present the results of tests for tail inequality, as defined in Section 5, equation (5.1). As in the main text, we write $\widehat{\gamma}=1 / \widehat{\alpha}$, where $\widehat{\gamma}$ equals the Hill estimator and its inverse is an estimate of the tail index. Due to the asymptotic normality of the Hill estimator, the null $H_{0}: \gamma_{1}=\gamma_{2}$ can be tested using the statistic already reported in (5.1):

$$
T_{12}=\frac{\widehat{\gamma}_{1}\left(m_{1}\right)-\widehat{\gamma}_{2}\left(m_{2}\right)}{\sqrt{\widehat{\sigma}^{2}\left(\gamma_{1}\right)+\widehat{\sigma}^{2}\left(\gamma_{2}\right)-2 \widehat{\operatorname{cov}}\left(\widehat{\gamma}_{1}, \widehat{\gamma}_{2}\right)}} \rightarrow N(0,1)
$$

Note that the variances in the denominator may be either calculated by using the bootstrap or analytically by exploiting the property $\widehat{\sigma}^{2}(\widehat{\gamma}) \approx$ $\frac{\widehat{\gamma}^{2}}{m}(m$ large). The covariance term, however, can only be calculated by the bootstrap.

\footnotetext{
${ }^{19}$ The explanations provided in this annex come from the two manuals "Datastream Global Equity Indices" and "Datastream Government Bond Indices" and some additional information given by the Datastream user helpline.
} 
Applying this test, the first table (Table 5) contains values of the statistic $T_{12}$ for testing the equality of left and right tail indexes for stock and bond markets respectively. In this case the two samples are independent and we can set the covariance term to zero. Variances are bootstrapped instead of calculated analytically. For a typical bootstrap replication number of 600 , however, we find that the bootstrapped variances are sufficiently close to their analytical counterparts and that there is convergence in the bootstrap. In the data at hand equality of left and right tails is only rejected for France at the 5\% significance level and for the US at the $1 \%$ significance level.

TABLE 5. Testing for the equality of left and right tail indexes

\begin{tabular}{ll|l}
\hline \hline \multicolumn{3}{c}{$\mathrm{H}_{0}: \gamma_{L}=\gamma_{R}\left(\alpha_{L}=\alpha_{R}\right)$} \\
\hline & Stocks & Bonds \\
\hline $\mathrm{GE}$ & 0.791 & 0.073 \\
$\mathrm{FR}$ & $2.111^{*}$ & -0.165 \\
$\mathrm{UK}$ & 0.591 & 0.335 \\
$\mathrm{US}$ & $3.153^{*}$ & 0.372 \\
$\mathrm{JP}$ & 1.203 & -1.413 \\
\hline \hline
\end{tabular}

Table 6 reports the tail inequality test results, comparing the relative thickness of stock and bond market return tails between G-5 countries and across asset classes. As shown in Tables 3 and 4 in the main text with the help of the $\mathrm{W}$ test by Peng (1999), one cannot assume independence in these cases and therefore the covariance term in $T_{12}$ has to be bootstrapped. For consistency we bootstrapped both variances and covariances using 600 replications again. At the $5 \%$ significance level, one can reject the equality of left stock and bond market return tails in France, the equality of left French and US bond market return tails and the equality of left Japanese stock market return tails and French bond market return tails. Even at the 1\% level one can reject for the left tails the equality of US stock market and German bond market extreme returns, US stock market and French bond market extreme returns and US stock market and Japanese bond market returns. For the right tails our data show a highly significant difference between French stock market and Japanese bond market extreme returns and a slightly less significant difference between French and Japanese extreme bond market returns. However, overall in most cases the test cannot reject the hypothesis of equal tail indexes in stock and bond markets of G-5 countries. 
TABLE 6 . Testing for the equality of tail indexes across different assets and countries

\begin{tabular}{|c|c|c|c|c|c|c|}
\hline & \multicolumn{3}{|c|}{ Left tail equality } & \multicolumn{3}{|c|}{ Right tail equality } \\
\hline & $S=S$ & $B=B$ & $S=B$ & $S=S$ & $B=B$ & $S=B$ \\
\hline GE & - & - & 1.067 & - & - & 0.359 \\
\hline FR & - & - & $1.973^{*}$ & - & - & -0.048 \\
\hline UK & - & - & 0.079 & - & - & -0.037 \\
\hline US & - & - & 1.903 & - & - & -1.032 \\
\hline JP & - & - & 1.313 & - & - & -1.138 \\
\hline \multicolumn{7}{|c|}{ Pairs $(S-B)$} \\
\hline GE-FR & -0.089 & 0.243 & 1.348 & 0.543 & 0.006 & 0.408 \\
\hline FR-GE & - & - & 1.436 & - & - & -0.044 \\
\hline GE-UK & 0.326 & -0.751 & 0.364 & -0.066 & -0.562 & -0.111 \\
\hline UK-GE & - & - & 0.704 & - & - & 0.357 \\
\hline GE-US & -1.354 & -1.329 & 0.122 & 0.339 & -1.148 & -0.689 \\
\hline US-GE & - & - & $2.532^{*}$ & - & - & 0.003 \\
\hline GE-JP & -0.235 & -0.373 & 0.807 & -0.026 & -0.467 & -1.649 \\
\hline JP-GE & - & - & 1.618 & - & - & 0.283 \\
\hline FR-UK & 0.517 & -0.930 & 0.492 & -0.510 & -0.597 & -0.634 \\
\hline UK-FR & - & - & 0.952 & - & - & 0.408 \\
\hline FR-US & -1.77 & $-2.122^{*}$ & 0.305 & -0.051 & -1.598 & -1.571 \\
\hline US-FR & - & - & $3.28 *$ & - & - & 0.008 \\
\hline FR-JP & -0.263 & -0.690 & 1.193 & -0.349 & $-2.402^{*}$ & $-2.626^{*}$ \\
\hline JP-FR & - & - & $2.167^{*}$ & - & - & 0.317 \\
\hline UK-US & -1.772 & -0.357 & -0.239 & 0.451 & -0.679 & -0.509 \\
\hline US-UK & - & - & 1.530 & - & - & -0.453 \\
\hline UK-JP & -0.706 & 0.365 & 0.454 & 0.026 & -1.698 & -1.295 \\
\hline JP-UK & - & - & 0.636 & - & - & -0.059 \\
\hline US-JP & 1.425 & 1.064 & $2.539^{*}$ & -0.278 & -1.444 & -1.898 \\
\hline JP-US & - & - & 0.516 & - & - & -0.445 \\
\hline
\end{tabular}

\section{REFERENCES}

[1] Borio, C.E.V. and R.N. McCauley (1996), 'The economics of recent bond yield volatility', BIS Economic Papers, no. 45, Basel, July.

[2] Boyer, B., Gibson, M. and M. Loretan (1997), 'Pitfalls in tests for changes in correlation', International Finance Discussion Paper, no. 5-97, Board of Governors of the Federal Reserve System, December.

[3] Bodart, V. and P. Reding (1999), 'Exchange rate regime, volatility and international correlations on bond and stock markets', Journal of International Money and Finance, 18, 133-51.

[4] Calvo, G.A. and E.G. Mendoza (2000), 'Rational contagion and the globalization of securities markets', Journal of International Economics, 51, 79-113.

[5] De Bandt, O. and P. Hartmann (2000), 'Systemic risk: a survey', ECB Working Paper, no. 35, European Central Bank, Frankfurt, November. 
[6] Domanski, D. and M. Kremer (2000), 'The dynamics of international asset price linkages and their effects on German stock and bond markets', in International Financial Markets and the Implications for Monetary and Financial Stability, BIS Conference Papers, no. 8, 134-158.

[7] Dumas, B. (1994), Partial Equilibrium versus general equilibrium models of the international capital market, in F. van der Ploeg (ed.), The Handbook of International Macroeconomics, Blackwell, 301-347.

[8] Eichengreen, B., Rose, A. and C. Wyplosz (1996), 'Contagious currency crises: first tests', Scandinavian Journal of Economics, 98, 463-484.

[9] Embrechts, P., Kliippelberg, C. and T. Mikosch (1997), Modelling Extremal Events, Springer, Berlin.

[10] Fleming, J., C. Kirby and B. Ostdiek, 1998, 'Information and volatility linkages in the stock, bond and money markets', Journal of Financial Economics, 49, 111-137.

[11] Friedman, B.M. and D.I. Laibson (1989), 'Economic implications of extraordinary movements in stock returns', Brookings Papers on Economic Activity, 2, 137-172.

[12] Goldie, C.M. and R.H. Smith (1987), 'Slow variation with remainder: theory and applications', Quarterly Journal of Mathematics (Oxford 2nd series), 38, 45-71.

[13] Haan, L. de, Jansen, D.W., Koedijk, K. and C.G. de Vries, 'Safety first portfolio selection, extreme value theory and long run asset risks', in J. Galambos ed., Proceedings from a Conference on Extreme Value Theory and Applications, Kluwer Press, 471-487.

[14] Haan, L. de and J. de Ronde (1998), 'Sea and wind: multivariate extremes at work', Extremes, 1, 7-45.

[15] Haan, L. de, S.I. Resnick, H. Rootzén and C.G. de Vries (1989), 'Extremal behaviour of solutions to a stochastic difference equation with applications to ARCH processes', Stochastic Processes and their Applications, 32, 213-224.

[16] Hamao, Y., Masulis, R.W. and V. Ng (1990), 'Correlations in price changes and volatility across international stock markets', Review of Financial Studies, 3, 281-307.

[17] Hill, B.M. (1975), 'A simple general approach to inference about the tail of a distribution', The Annals of Statistics, 3, 1163-1173.

[18] Huang, Xin (1992), 'Statistics of Bivariate Extreme Values', Tinbergen Institute Research Series, Ph.D. thesis no. 22, Erasmus University Rotterdam.

[19] Jansen, D.W. and C.G. de Vries (1991), 'On the frequency of large stock returns: putting booms and busts into perspective', Review of Economics and Statistics, 73, 19-24.

[20] Kaminsky, G.I. and C.M. Reinhart (2000), 'On crises, contagion and confusion', Journal of International Economics, 51, 145-168.

[21] King, M. and S. Wadhwani (1990), 'Transmission of volatility between stock markets', Review of Financial Studies, 3, 5-33.

[22] Lin, W.L., R. Engle, and T. Ito (1994), 'Do bulls and bears move across borders? International transmission of stock returns and volatility', Review of Financial Studies, 7, 507-538.

[23] Longin, F. and B. Solnik (1995), 'Is the correlation in international equity returns constant: 1960-1990?', Journal of International Money and Finance, $14,3-26$. 
[24] Longin, F. and B. Solnik (2000), 'Extreme correlation of international equity markets', mimeo, ESSEC Graduate School of Business, Paris, April (forthcoming Journal of Finance).

[25] Malliaris, A.G. and J.L. Urrutia (1992), 'The international crash of October 1987: causality tests,' Journal of Financial and Quantitative Analysis, 27, 353-363.

[26] Morgenstern, O. (1959), International Financial Transactions and the Business Cycle, Princeton University Press, Princeton (NJ).

[27] Peng, L. (1999), 'Estimation of the coefficient of tail dependence in bivariate extremes', Statistics \& Probability Letters, 43, 399-409.

[28] Ramchand, L. and R. Susmel (1998), 'Volatility and cross correlation across major stock markets', Journal of Empirical Finance, 5, 397-416.

[29] Sachs, J., Tornell, A. and A. Velasco (1996), 'Financial crises in emerging markets: the lessons from 1995', Brookings Papers on Economic Activity, 1, 147-198.

[30] Starica, C. (1999), 'Multivariate extremes for models with constant conditional correlations', Journal of Empirical Finance, 6, 515-553.

[31] Straetmans, S. (1998), Extreme Financial Returns and their Comovements, Tinbergen Institute Research Series, PhD. thesis no. 181, Erasmus University Rotterdam.

[32] Straetmans, S. (2000), Extremal spill-overs in equity markets, in P. Embrechts (ed.), Extremes and Integrated Risk Management, Risk Books (London), 187204.

[33] Susmel R. and R.F. Engle (1994), 'Hourly volatility spillovers between international equity markets', Journal of International Money and Finance, 13, $3-25$. 


\section{European Central Bank Working Paper Series}

I “A global hazard index for the world foreign exchange markets" by V. Brousseau and F. Scacciavillani, May 1999.

2 "What does the single monetary policy do? A SVAR benchmark for the European Central Bank” by C. Monticelli and O. Tristani, May 1999.

3 "Fiscal policy effectiveness and neutrality results in a non-Ricardian world" by C. Detken, May 1999.

4 "From the ERM to the euro: new evidence on economic and policy convergence among EU countries" by I. Angeloni and L. Dedola, May 1999.

5 “Core inflation: a review of some conceptual issues" by M. Wynne, May 1999.

6 "The demand for M3 in the euro area" by G. Coenen and J.-L. Vega, September 1999.

7 “A cross-country comparison of market structures in European banking” by O. de Bandt and E. P. Davis, September 1999.

8 “Inflation zone targeting” by A. Orphanides and V. Wieland, October 1999.

9 "Asymptotic confidence bands for the estimated autocovariance and autocorrelation functions of vector autoregressive models" by G. Coenen, January 2000.

10 "On the effectiveness of sterilized foreign exchange intervention" by R. Fatum, February 2000.

II "Is the yield curve a useful information variable for the Eurosystem?" by J. M. Berk and P. van Bergeijk, February 2000.

12 “Indicator variables for optimal policy" by L. E. O. Svensson and M. Woodford, February 2000.

13 “Monetary policy with uncertain parameters” by U. Söderström, February 2000.

14 "Assessing nominal income rules for monetary policy with model and data uncertainty" by G. D. Rudebusch, February 2000.

15 “The quest for prosperity without inflation” by A. Orphanides, March 2000.

16 "Estimating the implied distribution of the future short term interest rate using the LongstaffSchwartz model” by P. Hördahl, March 2000.

17 "Alternative measures of the NAIRU in the euro area: estimates and assessment" by S. Fabiani and R. Mestre, March 2000.

18 "House prices and the macroeconomy in Europe: Results from a structural VAR analysis" by M. lacoviello, April 2000. 
19 "The euro and international capital markets" by C. Detken and P. Hartmann, April 2000.

20 "Convergence of fiscal policies in the euro area" by O. De Bandt and F. P. Mongelli, May 2000.

21 "Firm size and monetary policy transmission: evidence from German business survey data" by M. Ehrmann, May 2000.

22 "Regulating access to international large value payment systems" by C. Holthausen and T. Rønde, June 2000.

23 “Escaping Nash inflation” by In-Koo Cho and T. J. Sargent, June 2000.

24 "What horizon for price stability" by F. Smets, July 2000.

25 "Caution and conservatism in the making of monetary policy" by P. Schellekens, July 2000.

26 "Which kind of transparency? On the need for clarity in monetary policy-making" by B. Winkler, August 2000.

27 "This is what the US leading indicators lead" by M. Camacho and G. Perez-Quiros, August 2000.

28 "Learning, uncertainty and central bank activism in an economy with strategic interactions" by M. Ellison and N. Valla, August 2000.

29 "The sources of unemployment fluctuations: an empirical application to the Italian case" by S. Fabiani, A. Locarno, G. Oneto and P. Sestito, September 2000.

30 "A small estimated euro area model with rational expectations and nominal rigidities" by G. Coenen and V. Wieland, September 2000.

3I "The disappearing tax base: Is foreign direct investment eroding corporate income taxes?" by R. Gropp and K. Kostial, September 2000.

32 "Can indeterminacy explain the short-run non-neutrality of money?" by F. De Fiore, September 2000.

33 "The information content of M3 for future inflation" by C. Trecroci and J. L. Vega, October 2000.

34 "Capital market development, corporate governance and the credibility of exchange rate pegs” by O. Castrén and T. Takalo, October 2000.

35 “Systemic risk: A survey” by O. De Bandt and P. Hartmann, November 2000.

36 "Measuring core inflation in the euro area" by C. Morana, November 2000.

37 "Business fixed investment: Evidence of a financial accelerator in Europe" by P. Vermeulen, November 2000. 
38 "The optimal inflation tax when taxes are costly to collect" by F. De Fiore, November 2000.

39 "A money demand system for euro area M3" by C. Brand and N. Cassola, November 2000.

40 "Financial structure and the interest rate channel of ECB monetary policy" by B. Mojon, November 2000.

41 "Why adopt transparency? The publication of central bank forecasts" by P. M. Geraats, January 2001.

42 "An area-wide model (AWM) for the euro area" by G. Fagan, J. Henry and R. Mestre, January 2001.

43 "Sources of economic renewal: from the traditional firm to the knowledge firm" by D. R. Palenzuela, February 2001.

44 "The supply and demand for eurosystem deposits - The first 18 months" by U. Bindseil and F. Seitz, February 200I.

45 "Testing the Rank of the Hankel matrix: a statistical approach" by G. Camba-Mendez and G. Kapetanios, February 200I.

46 "A two-factor model of the German term structure of interest rates" by N. Cassola and J. B. Luís, February 200 I.

47 "Deposit insurance and moral hazard: does the counterfactual matter?" by R. Gropp and J. Vesala, February 200I.

48 "Financial market integration in Europe: on the effects of EMU on stock markets" by M. Fratzscher, March $200 \mathrm{I}$.

49 "Business cycle and monetary policy analysis in a structural sticky-price model of the euro area” by M. Casares, March 200I.

50 "Employment and productivity growth in service and manufacturing sectors in France, Germany and the US” by T. von Wachter, March 2001.

5I "The functional form of the demand for euro area MI" by L. Stracca, March 200 I.

52 "Are the effects of monetary policy in the euro area greater in recessions than in booms?" by G. Peersman and F. Smets, March 200 I.

53 "An evaluation of some measures of core inflation for the euro area" by J.-L. Vega and M. A. Wynne, April 200I.

54 “Assessment criteria for output gap estimates" by G. Camba-Méndez and D. R. Palenzuela, April 200I.

55 "Modelling the demand for loans to the private sector in the euro area" by A. Calza, G. Gartner and J. Sousa, April 200I. 
56 "Stabilization policy in a two country model and the role of financial frictions" by E. Faia, April 200I.

57 "Model-based indicators of labour market rigidity" by S. Fabiani and D. Rodriguez-Palenzuela, April 200I.

58 "Business cycle asymmetries in stock returns: evidence from higher order moments and conditional densities" by G. Perez-Quiros and A. Timmermann, April 2001.

59 "Uncertain potential output: implications for monetary policy" by M. Ehrmann and F. Smets, April 200I.

60 "A multi-country trend indicator for euro area inflation: computation and properties" by E. Angelini, J. Henry and R. Mestre, April 2001.

6I "Diffusion index-based inflation forecasts for the euro area" by E. Angelini, J. Henry and R. Mestre, April 200I.

62 "Spectral based methods to identify common trends and common cycles" by G. C. Mendez and G. Kapetanios, April 200I.

63 "Does money lead inflation in the euro area?" by S. N. Altimari, May 200 I.

64 "Exchange rate volatility and euro area imports" by R. Anderton and F. Skudelny, May 200I.

65 "A system approach for measuring the euro area NAIRU" by S. Fabiani and R. Mestre, May 2001.

66 "Can short-term foreign exchange volatility be predicted by the Global Hazard Index?" by V. Brousseau and F. Scacciavillani, June 2001.

67 "The daily market for funds in Europe: Has something changed with the EMU?" by G. P. Quiros and H. R. Mendizabal, June 200I.

68 "The performance of forecast-based monetary policy rules under model uncertainty" by A. Levin, V. Wieland and J. C.Williams, July 2001.

69 "The ECB monetary policy strategy and the money market" by V. Gaspar, G. Perez-Quiros and J. Sicilia, July 2001.

70 "Central bank forecasts of liquidity factors: Quality, publication and the control of the overnight rate" by U. Bindseil, July $200 \mathrm{I}$.

71 “Asset market linkages in crisis periods" by P. Hartmann, S. Straetmans and C. G. de Vries, July 2001. 